\title{
Familial hyperaldosteronism type I
}

INSERM

\section{Source}

INSERM. (1999). Orphanet: an online rare disease and orphan drug data base. Familial hyperaldosteronism type I. ORPHA:403

Familial hyperaldosteronism type I (FH-I) is a rare heritable, glucocorticoid remediable form of primary aldosteronism (PA) characterized by early-onset hypertension, hyperaldosteronism, variable hypokalemia, low plasma renin activity (PRA), and abnormal production of 18-oxocortisol and 18-hydroxycortisol. 